\title{
Apoptotic Signaling Pathways in Glioblastoma and Therapeutic Implications
}

\author{
Silvia Anahi Valdés-Rives, ${ }^{1}$ Diana Casique-Aguirre, ${ }^{2}$ Liliana Germán-Castelán, \\ Marco A. Velasco-Velázquez, ${ }^{2,3}$ and Aliesha González-Arenas ${ }^{1}$ \\ ${ }^{1}$ Departamento de Medicina Genómica y Toxicología Ambiental, Instituto de Investigaciones Biomédicas, \\ Universidad Nacional Autónoma de México, Ciudad de México, Mexico \\ ${ }^{2}$ Departamento de Farmacología, Facultad de Medicina, Universidad Nacional Autónoma de México, Ciudad de México, Mexico \\ ${ }^{3}$ Unidad Periférica de Investigación en Biomedicina Translacional, ISSSTE C.M.N. 20 de Noviembre, Facultad de Medicina, \\ Universidad Nacional Autónoma de México, Ciudad de México, Mexico
}

Correspondence should be addressed to Marco A. Velasco-Velázquez; marcovelasco@unam.mx and Aliesha González-Arenas; alieshagonzalez@gmail.com

Received 28 July 2017; Revised 22 September 2017; Accepted 28 September 2017; Published 12 November 2017

Academic Editor: Francesco Pasqualetti

Copyright (c) 2017 Silvia Anahi Valdés-Rives et al. This is an open access article distributed under the Creative Commons Attribution License, which permits unrestricted use, distribution, and reproduction in any medium, provided the original work is properly cited.

Glioblastoma multiforme (GBM) is the most hostile type of brain cancer. Its aggressiveness is due to increased invasion, migration, proliferation, angiogenesis, and a decreased apoptosis. In this review, we discuss the role of key regulators of apoptosis in GBM and glioblastoma stem cells. Given their importance in the etiology and pathogenesis of GBM, these signaling molecules may represent potential therapeutic targets.

\section{Introduction}

The most frequent and aggressive human brain tumor is glioblastoma multiforme (GBM), which is a glial cell-derived tumor (glioma) with high malignant potential that has a tendency to invade the surrounding tissue [1]. These tumors arise either from glioma altered cells that facilitate tumor initiation and progression or from glioblastoma stem cells (GSCs) that possess the ability to self-renew and initiate tumor formation [2].

GBM originates anywhere in the brain but is mainly located in the cerebral cortex, appearing more frequently in adults between 40 and 60 years old [1]. GBM represent the maximal progression stage of astrocytomas, which are classified according to their histopathological and molecular features into four grades (I-IV). The survival of patients is inversely related to tumor grade [1]. GBM patients have a median survival of just 4.6 months. In optimally treated patients, the median survival increases to 14 months with a
$26 \%$ two-year survival rate $[3,4]$. The classical chemotherapeutic drug used in the treatment of this kind of tumors is Temozolomide, an agent that alkylates DNA at the N-7 or O6 positions of guanine residues; therefore, it triggers cell death [5].

GBM can arise de novo (primary GBM) or transform from a lower grade astrocytoma (secondary GBM); thus each is characterized by distinct genetic events. GBM de novo frequently has EGFR amplification (34\%) and PTEN loss/mutations (24\%), while secondary GBM is characterized by TP53 mutations (65\%) and IDH1 mutations (70\%). Despite these differences, both tumors have the same histopathological features [6-8]. Nevertheless, primary GBM are more aggressive and less responsive to treatment compared to secondary ones.

\section{GBM Intertumor Heterogeneity}

A catalog of genomic abnormalities of GBM has been reported through the Cancer Genome Atlas [9], which 
allowed Verhaak's group to classify GBM into four subtypes: classical, mesenchymal, proneural, and neural [10]. The classical subtype has EGFR amplification and loss of TP53 and CDKN2A. It also harbors an EGFRvIII mutation constitutively active due to the deletion of exons 2-7 of the EGFR gene. This subtype presents Nestin overexpression and has activated the Notch and $\mathrm{SHH}$ pathways [10]. The mesenchymal subtype is associated with poor overall survival and contains NF1 mutations and loss of IDH1, PIK3R1, and PDGFRA. It presents overexpression of MET and CHI3L1 and activation of the NFKB pathway [10].

The proneural subgroup has augmented frequency of mutations in IDH1 and TP53 and amplifications of PDGFRA and PIK3CA/PIK3R1. This group has the highest percentage of younger patients [10]. The neural subtype has elevated levels of neural markers such as NEFL, but it has no unique distinguishing alterations from other classes, although elevated rates of EGFR, TP53, and PTEN mutations are observed [10].

To date, the differences on apoptotic pathways between GBM subtypes have not been clarified. The identification of the mechanisms leading to decreased apoptosis in each subtype might lead to better therapies in the future. For example, the proneural subtype could be dependent on the $\mathrm{PI} 3 \mathrm{~K} / \mathrm{AKT}$ pathway for survival, whereas the mesenchymal subtype could be dependent on the $\mathrm{TNF} / \mathrm{NF} \kappa \mathrm{B}$ pathway. Thus, epidemiological, molecular, and pharmacological studies are required to identify the best therapeutic strategies for each GBM subtype.

\section{Signals Regulating Apoptosis in GBM}

Apoptosis is an essential mechanism by which the homeostatic balance between cell proliferation and cell death is maintained [24, 25]. In apoptosis, cells activate a molecular pathway that leads them to die in case they become damaged and the cell mechanism fails to repair it. This process can be achieved through the activation of two molecular pathways, the extrinsic and the intrinsic pathway. Both pathways lead to the proteolytic activation caspases $[24,25]$. These proteases induce cell changes that include chromatin condensation, DNA fragmentation, membrane blebbing, and cell shrinkage $[24,25]$. The extrinsic pathway is triggered from outside the cell by proapoptotic ligands that activate cell surface death receptors. After binding to them, the formation of a death-inducing signaling complex (DISC) is induced. This protein complex activates procaspase- 8 and procaspase- 10 and, eventually, caspase-3 to execute apoptosis [24, 25]. The intrinsic pathway is activated from inside the cell by severe cell stress, such as DNA damage. The latter promotes mitochondrial outer membrane permeabilization and activation of BH3-only proapoptotic B-cell lymphoma 2 (BCL-2) family proteins. This allows the release of proapoptotic proteins, like cytochrome $c$ and second mitochondria-derived activator of caspase (Smac) from the mitochondria into the cytosol. Cytochrome $\mathrm{c}$ forms a complex with apoptotic proteaseactivating factor-1 (Apaf-1) known as the apoptosome to activate caspase-9. This caspase, in turn, activates the effector caspase- 3 , caspase- 6 , and caspase-7, which in turn executes apoptosis $[24,25]$.

GMB cells show intrinsic deregulation in apoptotic cell death. Furthermore, antitumor drugs and radiotherapy affect the pathways that control apoptosis in GBM cells, activating prosurvival mechanisms that make the treatments ineffective. Thus, research into the possible enhancement of apoptosis of GBM is a primary goal in the development of new and more effective treatments. In the present review, we summarize the role of apoptosis-controlling intracellular pathways in GBM cells (Figure 1) and discuss their importance as therapeutic targets. Finally, we highlight the differences in apoptosis signaling in the subpopulation of GSCs.

3.1. PI3K/AKT/mTOR Pathway Inhibits GBM Apoptosis. PI3K is a kinase that plays a central role in signaling pathways controlling cell survival, proliferation, motility, angiogenesis, and apoptosis [25-27]. The activation of PI3K through its cognate cell surface receptors, such as growth factor receptors, phosphorylates the plasma membrane lipid phosphatidylinositol4,5-biphosphate $\left(\mathrm{PIP}_{2}\right)$ producing the second messenger phosphatidylinositol-3,4,5-triphosphate $\left(\mathrm{PIP}_{3}\right)$. $\mathrm{PIP}_{3}$ induces the accumulation of signaling proteins such as AKT and the phosphoinositide-dependent kinase 1 (PDK1) by direct binding. Association with $\mathrm{PIP}_{3}$ at the cell membrane results in AKT phosphorylation by induced-proximity to PDK1 [26]. After its activation, AKT regulates downstream targets like GSK-3 $\beta$, Bad, and mTOR complex to name a few $[26,28]$.

It has been reported that PI3K/AKT signaling is probably deregulated in $80 \%$ of all GBM. The latter is estimated because the majority of tumors have overexpression of EGFRvIII variant and loss of PTEN (see Section 3.2) [10, 29]. Furthermore, there is a direct correlation between AKT activation and the histopathological grade of glioma with $84 \%$ of GBM positive to phosphorylated AKT (pAKT), whereas it is scarcely detected in healthy tissue [30]. AKT is the intermediary of PI3K-dependent cell survival responses since its absence abrogates these effects.

In GBM, pAKT induces overexpression of MDM2 protooncogene, which is an important negative regulator of p53 [31-33] and inhibits the apoptosis-inducing protein Bad that is inactive when phosphorylated [34]. Moreover, AKT can indirectly activate mTOR, which is a protein kinase critical for cell proliferation deregulated in GBM $[11,35]$. mTOR acts as both a downstream effector and an upstream regulator and its signaling is carried out by two protein complexes known as mTORC1 and mTORC2. mTORC1 regulates cell growth, while mTORC2 phosphorylates AKT at Ser-473 and then further takes part in cell survival, metabolism, proliferation, and cytoskeletal organization $[11,36]$.

The impact of PI3K/AKT/mTOR pathway in cell survival suggests that its inhibition may lead to increase apoptosis and to be of therapeutic value in GBM [35]. Additionally, its inhibition could increase the cytotoxic potential of the glioma-associated microglia because it polarizes microglial cells towards the M1 phenotype, with cytotoxic activities, and prevents the induction of the M2 that promotes tumor growth [36]. 


\section{(B) TNFR1/TNF- $\alpha$ pathway}

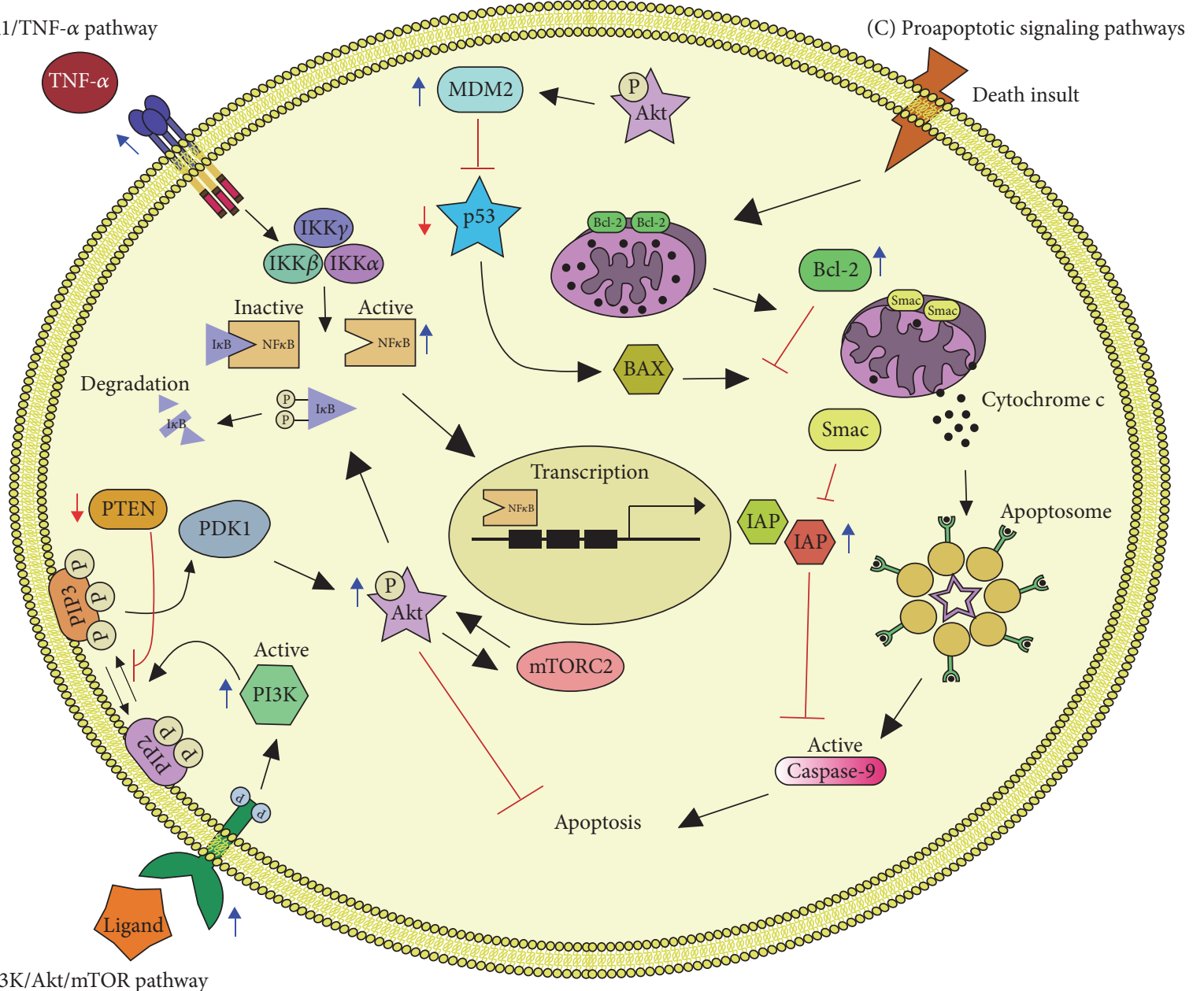

(A) PI3K/Akt/mTOR pathway

FIGURE 1: Apoptotic Pathways in Glioblastoma. (A) The activation of PI3K ensues by the binding of a ligand to a receptor tyrosine kinase (RTK). The RTK activation by phosphorylation of its intracellular domain activates the catalytic subunit of PI3K; this results in the generation of PIP 3 from $\mathrm{PIP}_{2}$. PIP ${ }_{3}$ activates PDK1 which in turn phosphorylates AKT. AKT phosphorylates many downstream targets, including I $\kappa \mathrm{B}$ to induce $\mathrm{NF} \kappa \mathrm{B}$ activation and mTORC2 and MDM2 to induce cell survival. PTEN antagonizes the PI3K pathway by dephosphorylating the second messenger $\mathrm{PIP}_{3}$ to $\mathrm{PIP}_{2}$. (B) TNF- $\alpha$ is a potent activator of NF $\kappa \mathrm{B}$, which binds to its receptor (TNFR1) enabling the degradation of I $\kappa \mathrm{B}$, by the IKK complex. This allows the translocation of $\mathrm{NF} \kappa \mathrm{B}$ to the nucleus where it regulates the expression of its target genes such as IAPs, which can directly bind and inhibit caspase-3, caspase-7, and caspase-9. (C) A variety of death stimuli can induce the release of cytochrome C from the mitochondria and trigger the formation of the apoptosome with subsequent caspase cascade activation leading to apoptosis. BCL-2 controls the mitochondrial membrane permeability and can inhibit this process, whereas BAX stimulates it. BAX is activated by p53 but p53 is negatively regulated by MDM2. Smac is located within the mitochondrial intermembrane space and enters the cytosol when cells undergo apoptosis to inhibit IAPs. Blue arrows denote overexpression and red arrows denote loss of function.

Several dual inhibitors targeting PI3K and mTOR have been developed (Table 1). For example, PI-103 and NVPBEZ235 induce growth blockage and autophagy induction better than does the mTORC1 inhibitor rapamycin, by blocking the phosphorylation of AKT and mTORC1 target 4EBP1 $[11,35]$. However, temsirolimus, a small-molecule inhibitor of mTOR, displays a limited clinical efficacy, since only a subset of patients with high levels of phosphorylated p70s6 kinase in tumor samples were more likely to benefit from treatment. Temsirolimus increased 2.3 months the median survival of GBM patients [14].

At the moment, targeted therapy towards PI3K/AKT/ mTOR pathway has not achieved satisfactory results. For further studies, it is important to analyze the reason why some treatments are more beneficial than others taking the following into consideration as possible limiting factors: the number of targets they have, the capacity to cross the blood brain barrier and to reach an optimal concentration in the tumor microenvironment, heterogeneity of GBM, and the activation of alternative signaling pathways.

3.2. PTEN Loss in GBM Apoptosis. PTEN is a tumor suppressor gene that antagonizes the $\mathrm{PI} 3 \mathrm{~K} / \mathrm{AKT} / \mathrm{mTOR}$ pathway by functioning as a lipid phosphatase. PTEN acts on the lipid signaling intermediate $\mathrm{PIP}_{3}$ to convert it into $\mathrm{PIP}_{2}$, thereby preventing the activation of AKT [37]. PTEN is a 
TABLE 1: Summary of drugs targeting apoptotic pathways in GBM.

\begin{tabular}{|c|c|c|c|c|c|}
\hline Drug & Target & Mechanism of action & STAGE* & $\begin{array}{c}\text { ID } \\
\text { (https://clinicaltrials.gov) }\end{array}$ & Reference \\
\hline PI-103 & $\begin{array}{l}\text { AKT \& } \\
\text { mTORC1 }\end{array}$ & $\begin{array}{c}\text { Prevents } \\
\text { phosphorylation of } \\
\text { AKT and 4EBP1 }\end{array}$ & $\mathrm{PC}$ & & {$[11]$} \\
\hline BKM120 & PI3K & $\begin{array}{l}\text { Direct inhibition of } \\
\text { PI3K }\end{array}$ & $\mathrm{Ph} \mathrm{I}$ & NCT01339052 & {$[12]$} \\
\hline NVP-BEZ235 & $\mathrm{PI} 3 \mathrm{~K}$ and $\mathrm{mTOR}$ & $\begin{array}{c}\text { ATP-competitive } \\
\text { inhibitor of PI3K and } \\
\text { mTOR }\end{array}$ & $\mathrm{Ph}$ II & NCT02430363 & {$[13]$} \\
\hline Temsirolimus & mTOR & $\begin{array}{l}\text { Direct inhibition of } \\
\text { mTOR }\end{array}$ & $\mathrm{Ph}$ II & NCT00016328 & [14] \\
\hline Bortezomib & $\mathrm{I} \kappa \mathrm{B}$ complex & $\begin{array}{c}\text { Proteasome inhibitor } \\
\text { that blocks } \mathrm{I} \kappa \mathrm{B} \\
\text { degradation }\end{array}$ & $\mathrm{Ph}$ II & NCT00998010 & {$[15]$} \\
\hline BAY 11-7082 & $\mathrm{I} \kappa \mathrm{K}$ & $\begin{array}{c}\text { Inhibits } \mathrm{I} \kappa \mathrm{K} \text { and } \\
\text { prevents } \mathrm{NF} \kappa \mathrm{B} \\
\text { nuclear translocation }\end{array}$ & $\mathrm{PC}$ & & {$[16]$} \\
\hline DHMEQ & $\mathrm{NF} \kappa \mathrm{B}$ & $\begin{array}{l}\text { Inhibits } \mathrm{NF} \kappa \mathrm{B} \text { DNA } \\
\text { binding }\end{array}$ & PC & & [17] \\
\hline ABT-737 & BCL-2 & $\begin{array}{l}\text { Direct biding and } \\
\text { inhibition of BCL-2 }\end{array}$ & PC & & {$[18]$} \\
\hline AT-101 & $\begin{array}{c}\text { BCL-2, BCL-XL, } \\
\text { MCL-1 \& } \\
\text { BCL-W }\end{array}$ & $\begin{array}{l}\text { BH3 mimetic and } \\
\text { BCL-2 family } \\
\text { inhibitor }\end{array}$ & $\mathrm{Ph}$ II & NCT00540722 & [19] \\
\hline $\begin{array}{l}\text { ABT-263/GX15- } \\
070\end{array}$ & BCL-2 \& MCL-1 & $\begin{array}{l}\text { Direct biding and } \\
\text { inhibition of BCL-2 } \\
\text { and MCL-1 }\end{array}$ & PC & & {$[20]$} \\
\hline LBW242/BV6 & $\begin{array}{l}\text { XIAP, } \\
\text { c-IAP1, \& } \\
\text { c-IAP2 }\end{array}$ & Smac mimetic & $\mathrm{PC}$ & & [21-23] \\
\hline
\end{tabular}

${ }^{*}$ PC: preclinical; Ph I: phase 1 clinical trial; Ph II: phase 2 clinical trial.

unique phosphatase; there are no PTEN-related proteins that compensate for its loss of function. It has been reported that PTEN is inactivated in GBM. Mutations in PTEN have been associated with the malignant evolution of astrocytic tumors since they are most frequently found in GBM and rarely in lower grades $[38,39]$. PTEN mRNA levels are much lower in glioma tissue compared with benign brain tumors and tumor-adjacent normal tissues [40]. The lack of PTEN function is associated with poor survival rather than with tumor initiation in anaplastic astrocytoma and GBM [41]. There is extensive evidence suggesting that the loss of PTEN by mutation, methylation, or deletion leads to a decreased apoptosis [37, 42]. The loss of PTEN is frequent in GBM, and therefore it is difficult to target it for therapy. Recently, a correction of PTEN mutation in GBM cell lines was reported [43]. Using adenoassociated virus-mediated gene edition PTEN allele was corrected in two GBM cell lines-42MGBA and T98G. In both cases, the edition resulted in reduced cellular proliferation in an AKT-dependent (42MGBA) and AKT-independent (T98G) manner [43]. Thus, genome editing technologies can be applied to correct genetic mutations in a gain-of-function manner $[44,45]$. Whether these strategies are useful for GBM treatment in patients and whether tumor editing is possible in the brain remain to be clarified.

3.3. Role of $N F \kappa B$ in GBM Apoptosis. $\mathrm{NF} \kappa \mathrm{B}$ [nuclear factor kappa $B$ ] is a transcription factor for a large group of genes which are involved in apoptosis, cell adhesion, proliferation, and inflammation [46]. $\mathrm{NF} \kappa \mathrm{B}$ has 5 subunits: p50, p52, p65, RelB, and c-Rel. These subunits exist in homo- or heterodimers, the most abundant dimer being p65/p50. $\mathrm{NF} \kappa \mathrm{B}$ is sequestered in the cytoplasm by $\mathrm{I} \kappa \mathrm{B}$. This association is rapidly interrupted by diverse signals like cytokines, pathogens, stress signals, and radiation [47]. These signals activate a kinase complex known as $\mathrm{I} \kappa \mathrm{K}$. I $\kappa \mathrm{K}$ complex is formed of three subunits $(\alpha, \beta$, and $\gamma$ ) which phosphorylates and inactivates $\mathrm{I} \kappa \mathrm{B}$, which allows the nuclear translocation of $\mathrm{NF} \kappa \mathrm{B}$ and the subsequent regulation of its target genes including those of Inhibitor of Apoptosis Proteins (IAPs) [47, 48]. Levels of activated $\mathrm{NF} \kappa \mathrm{B}$, measured by phosphorylation of the subunits p65/p50, are much higher in GBM compared with that of healthy tissue, and they present a positive correlation with glioma grade [30]. Approximately $96 \%$ of the tumors analyzed in two independent studies express activated $\mathrm{NF} \kappa \mathrm{B}[30,49]$. Similarly, it has been found that 
$\mathrm{NF} \kappa \mathrm{B}$ is constitutively activated in several human-derived glioblastoma cell lines like U251-MG, U87-MG, and U373 [30].

There are two mechanisms of $\mathrm{NF} \kappa \mathrm{B}$ activation in GBM: AKT phosphorylation of $\mathrm{I} \kappa \mathrm{B}$ and TNF- $\alpha / \mathrm{TNFR} 1$ pathway $[30,49-51]$. Tumor necrosis factor- $\alpha$ (TNF- $\alpha$ ) induces the main antiapoptotic activity of $\mathrm{NF} \kappa \mathrm{B}$ through its death receptors TNFR1 by suppression of caspase- 8 activation $[50,52$, 53]. The expression of TNFR1 is elevated in GBM compared with the lower grade and scarcely detectable in astrocytomas and healthy brain tissue suggesting a vital role in these tumors [54].

Enhancement of apoptosis by targeting $\mathrm{NF} \kappa \mathrm{B}$ has had several approaches (Table 1). Bortezomib is a proteasome inhibitor that blocks $\mathrm{I} \kappa \mathrm{B}$ proteins degradation, among others. It has been evaluated in phase 1 clinical trial either alone or in combination with Temozolomide and radiotherapy [15, 55]. The usage of bortezomib alone showed a partial clinical efficacy although it was not reflected on the overall survival. The combined therapy bortezomib with Temozolomide and radiotherapy was reported to be well tolerated and safe. Currently, a phase 2 trial is active with an overall survival of two years for newly diagnosed GBM undergoing this therapy [15, 55]. BAY 11-7082, an I $\kappa \mathrm{K}$ inhibitor, effectively inhibits $\mathrm{NF} \kappa \mathrm{B}$ which leads to lower chemoresistance, improves sensitivity to photodynamic therapy, and induces senescence [16]. To date, no clinical trials have been reported for this inhibitor. Dehydroxymethylepoxyquinomicin (DHMEQ) is an $\mathrm{NF} \kappa \mathrm{B}$ inhibitor undergoing preclinical testing [17], where it has shown that inhibition of $\mathrm{NF} \kappa \mathrm{B}$ activation and its nuclear translocation lead to increased apoptosis $[17,56]$.

$\mathrm{NF} \kappa \mathrm{B}$ influences multiple cellular processes in normal cells. Therefore, care must be taken when blocking the $\mathrm{NF} \kappa \mathrm{B}$ pathway to minimize off-target effects and unwanted toxicities. Dual or multitarget therapies may prove more beneficial by targeting several regulators of this pathway, although no studies or drugs have been reported to date.

3.4. BCL-2 in GBM Apoptosis. The B-cell lymphoma-2 (BCL2) is a family of proteins ranging in size from 20 to $37 \mathrm{kDa}$ : BCL-2, BCL- $\mathrm{x}_{\mathrm{L}}$, MCL-1, BCL-w, BFL-1/A1, BCL-B, BAX, $\mathrm{BAK}$, and $\mathrm{BOK}$ [57]. This family participates in cell death and modulates different processes that include apoptosis (BAX, $\mathrm{BAK}$, and BID), necrosis (BAX), and autophagy inhibition (BCL-2, BCL- $\mathrm{x}_{\mathrm{L}}, \mathrm{MCL}-1$, and BCL-w) [57]. The $26 \mathrm{kDa}$ form of BCL-2 protein is localized on the outer mitochondrial membrane, nuclear envelope, and endoplasmic reticulum $[58,59]$. This protein is able to regulate the outer mitochondrial membrane permeability of transition pores by blocking proapoptotic proteins like BAX and BAK. Thus, it inhibits the release of cytochrome $c$ from the mitochondria and prevents the formation of the apoptosome, activation of caspases, and eventually cell death [60]. BCL-2 protein is overexpressed in GBM [61] and recurrent tumors [62]. In vitro studies have shown that the use of antisense constructs or chemical inhibitors, such as ABT-737, is capable of mitigating the antiapoptotic effects of BCL-2 and renders the cells sensitive to cytotoxic treatments (Table 1 ) $[18,63]$. However, GBM has shown resistance to ABT-737 and a similar compound ABT263 by upregulating MCL-1, another antiapoptotic member of the BCL-2 family. The combined use of ABT-263 and GX15070, an inhibitor of MCL-1, has shown to effectively reverse this resistance [20]. Preclinical studies seem promising, especially when inhibitors are in combination with additional chemotherapy agents [64]. Once the benefit of using BCL2 family inhibitors has been established, an obstacle to overcome will be to evaluate if these drugs are able to cross the blood brain barrier, since in vivo studies have only been done with subcutaneous tumors of GBM cell lines.

3.5. Inhibitor of Apoptosis Proteins (IAPs) Role in GBM. IAPs comprise a family of proteins which have a common domain of 70-amino-acid baculovirus repeats (BIR domains) in their structure. This family of proteins consists of 8 members: NAIP, XIAP, cIAP1, cIAP2, ILP2, livin, survivin, and BRUCE $[65,66]$. These proteins can inhibit apoptosis by neutralizing active caspases, through their degradation or by blocking caspase-3, caspase- 7 , and caspase- 9 by binding to their catalytically active pockets [65]. Smac is a protein that promotes cytochrome $\mathrm{c}$ release and TNF- $\alpha$ dependent apoptosis by direct binding and inhibition of IAPs (XIAP, c-IAP1, and c-IAP2), at the same time inhibiting the TNF$\alpha /$ TNFR antiapoptotic pathway [66].

Within the genomic alterations commonly detected in GBM is the amplification of chromosomal band 11q22, which contains IAP1- and IAP2-encoding genes [67, 68]. Three types of IAPs are widely expressed in glioma cell lines at both mRNA and protein level [69]. They participate in cell survival under apoptotic stimuli. This suggests that IAPs may play a role in the resistance of gliomas to apoptosis induced by radio- and chemotherapy [69]. In accordance, the inhibition of IAPs, namely, XIAP and survivin, by antisense oligos sensitizes tumor cells to death [70, 71]. Smac mimetics (e.g., LBW242 and BV6) can also sensitize cancer cells to chemoand radiotherapy and induce regression of malignant gliomas in vivo (Table 1) $[21-23,66]$. LBW242, in combination with the PDGFR kinase inhibitor AMN107, triggered apoptosis in human GBM cells in vitro and had synergistic effects in mouse models of GBM and primary human GBM neurospheres [21]. In the same fashion, BV6 sensitizes GBM to Temozolomide which induces caspase- 8 activation and apoptosis [22].

In vitro and in vivo data show IAPs as promising targets in anticancer therapy, although the efficacy and tolerability of adverse effects of these agents remain to be determined in clinical trials.

\section{Apoptosis Control in Glioblastoma Stem Cells (GSCs)}

GBM tumors present heterogeneous clonal subpopulations. For example, up to three different molecular subtypes have been found in the same patient, with a prevalence of mesenchymal subtype in males $[4,72,73]$. This clonal divergence can be caused by the genetic instability intrinsic to cancer cells combined with the selective pressure elicited by therapeutic 
interventions [74]. Furthermore, intratumor heterogeneity is increased by cell plasticity, which allows glioblastoma cells to dedifferentiate to a stem cell-like state [75].

GSCs have functional properties distinct to the rest of glioblastoma tumor cells. They can self-renew and generate progenitor cells, creating a hierarchy consisting of subpopulations of tumorigenic and nontumorigenic cells [76]. GSCs drive GBM growth and promote tumor recurrence and drug resistance [77]. Thus, the presence of GSCs is associated with aggressive tumors and higher mortality rates [77]. Accordingly, the monitoring of the intratumor heterogeneity using GSCs molecular markers in the initial surgery and surgery for recurrent GBM may be important for the most effective management of GBM [78]. Furthermore, GSCs have been pointed as targets for the development of better therapies for this kind of tumors [79].

GCSs express different molecular markers associated with their maintenance, including pluripotency factors such as SOX2, Nanog, and OCT4 [80, 81]. However, GSCs are commonly identified by CD133 or CD44 expression. CD133 is a membrane glycoprotein encoded by prominine-1 gene (PROM1). CD133 is expressed in hematopoietic stem cells, endothelial progenitor cells, and neural stem cells [82, 83], and it is essential for the maintenance of GSCs [80]. CD133 silencing in GSCs reduces proliferation, self-renewal, and tumorigenic capacity. Accordingly, GBM patients with high CD133 levels show poor clinical prognosis [84].

CD44 is a surface receptor that preferentially binds to hyaluronic acid (HA) [85]. In cancer cells, CD44 modulates adhesion, migration, and cell division. CD44 is expressed in GSCs and stem cells from other tumors such as breast and colon carcinomas and leukemias [86-88]. In brain tumors, CD44 expression is associated with increased tumor initiation and progression. In a mouse model of glioma, $\mathrm{CD} 44^{+/+}$animals developed significantly more high-grade gliomas and had shorter survival times than did CD $44^{+/-}$ or $\mathrm{CD} 44^{-/-}$mice [89]. Accordingly, CD44 showed higher expression in higher-grade brain tumors [90].

Recent evidence suggests that $\mathrm{CD} 133^{+}$and $\mathrm{CD} 44^{+}$cells represent two different populations of GSCs with different transcriptomic signatures and cell functions. GSCs expressing CD133 display a proneural phenotype, while $\mathrm{CD} 44^{+} \mathrm{GSCs}$ are mesenchymal [91]. Patients with tumor CD44 expression have more aggressive, angiogenic, and radiation-resistant phenotypes but respond better to Temozolomide. In contrast, patients with CD133 expression had a better response to radiotherapy [92]. Moreover, $\mathrm{CD} 133^{+}$and $\mathrm{CD} 44^{+}$cells can be found simultaneously in xenotransplants generated from patients-derived glioma cells. Hypoxia induces a change from $\mathrm{CD} 44^{+}$to $\mathrm{CD} 133^{+}$, but chemotherapy switches from $\mathrm{CD} 133^{+}$ to $\mathrm{CD} 44^{+}$[78]. Thus, cell plasticity allows the bidirectional conversion between the two phenotypes in response to environmental factors.

4.1. PI3K/AKT/mTOR Pathway Also Controls Apoptosis in GSCs. The PI3K/AKT/mTOR signaling cascade promotes proliferation and survival in GSCs. The evidence supporting this idea comes mainly from the effects of inhibitors of the pathway in GSCs. For example, the use of FC85, a dual AKT/mTOR inhibitor, induces apoptosis both in glioblastoma cell lines and in GSC-enriched cultures. Furthermore, the reactivation of p53 with an MDM2 inhibitor enhances the apoptotic effect of FC85 in GSCs [33]. NVP-BEZ235 is an imidazoquinoline that acts as a dual inhibitor of PI3K/mTOR, and it is currently in phase 1 and 2 clinical trials for advanced solid tumors and metastatic cancer (Table 1). NVP-BEZ235 inhibits proliferation and enhances radiosensitivity in a cell line derived from $\mathrm{CD}_{133^{+}}$GSCs. The combination of NVPBEZ235 and radiation blocks cell proliferation and increases apoptosis. Such effects correlate with the increased expression of the proapoptotic proteins BID, Bax, and caspase- 3 as well as with augmented radiation-induced DNA damage [13]. The $\mathrm{PI} 3 \mathrm{~K}$ pathway is also active in cancer stem cells from prostate [93] and breast [94] tumors, highlighting the role of this pathway in the biology of cancer stem cells.

4.2. Apoptosis Signals Specific of GSCs. GSCs are phenotypically and biologically different to the GMB bulk cells. Proteins that are differentially expressed in GSCs can regulate their survival. The examples provided below show that this is the case but also demonstrate that GSCs are sensitive to apoptosis-induction when these molecules are targeted.

Signal Transducer and Activator of Transcription-3 (STAT3) is a transcription factor whose activation plays a crucial role in proliferation, apoptosis-induction, and differentiation of GSCs. STAT-3 knock-down reduces the percentage of $\mathrm{CD}_{133^{+}}$cells and neurosphere-formation in GSC-enriched cultures and decreases tumorigenicity in vivo $[95,96]$. In human GBM cells grown as neurospheres to increase GSC content, pharmacological inhibition of STAT-3 dimerization decreases the expression of pluripotency, proproliferative, and antiapoptotic genes. The treatment reduces BCL-XL and survivin expression, inducing caspase- 3 activation and apoptosis in GSCs [97]. Similarly, inhibition of STAT3 with the natural compound cardamonin $\left(2^{\prime}, 4^{\prime}\right.$-dihydroxy$6^{\prime}$-methoxychalcone) suppresses STAT3 downstream gene expression including BCL-XL, survivin, BCL-2, Mcl-1, and VEGF. Consequently, cardamonin inhibits proliferation and induces apoptosis in $\mathrm{CD}_{133^{+}}$GSCs [98].

The Notch signaling pathway is overactivated in GBM, particularly in those with EGFR amplification (reviewed in [99]). The treatment of GBM neurosphere cultures with $\gamma$ secretase inhibitors to prevent Notch cleavage reduces the number of $\mathrm{CD}_{13} 3^{+}$cells and in vitro clonogenicity, demonstrating that the Notch pathway is important for stemness maintenance. Blockage of the Notch pathway induces both decreased proliferation and increased apoptosis. The latter effect is associated with an inhibition of AKT- and STAT3phosphorylation and an increase in the proapoptotic cleaved form of caspase-3 [100]. These data suggest that Notch crosstalk with PI3K/AKT and STAT3 signaling promotes the survival of GSCs.

Finally, the Hedgehog pathway has also been implicated in the control of apoptosis of GSCs. Arsenic trioxide (AT) can directly bind and inhibit GLI proteins $[101,102]$ which are transcriptional effectors of the Hedgehog pathway. The 


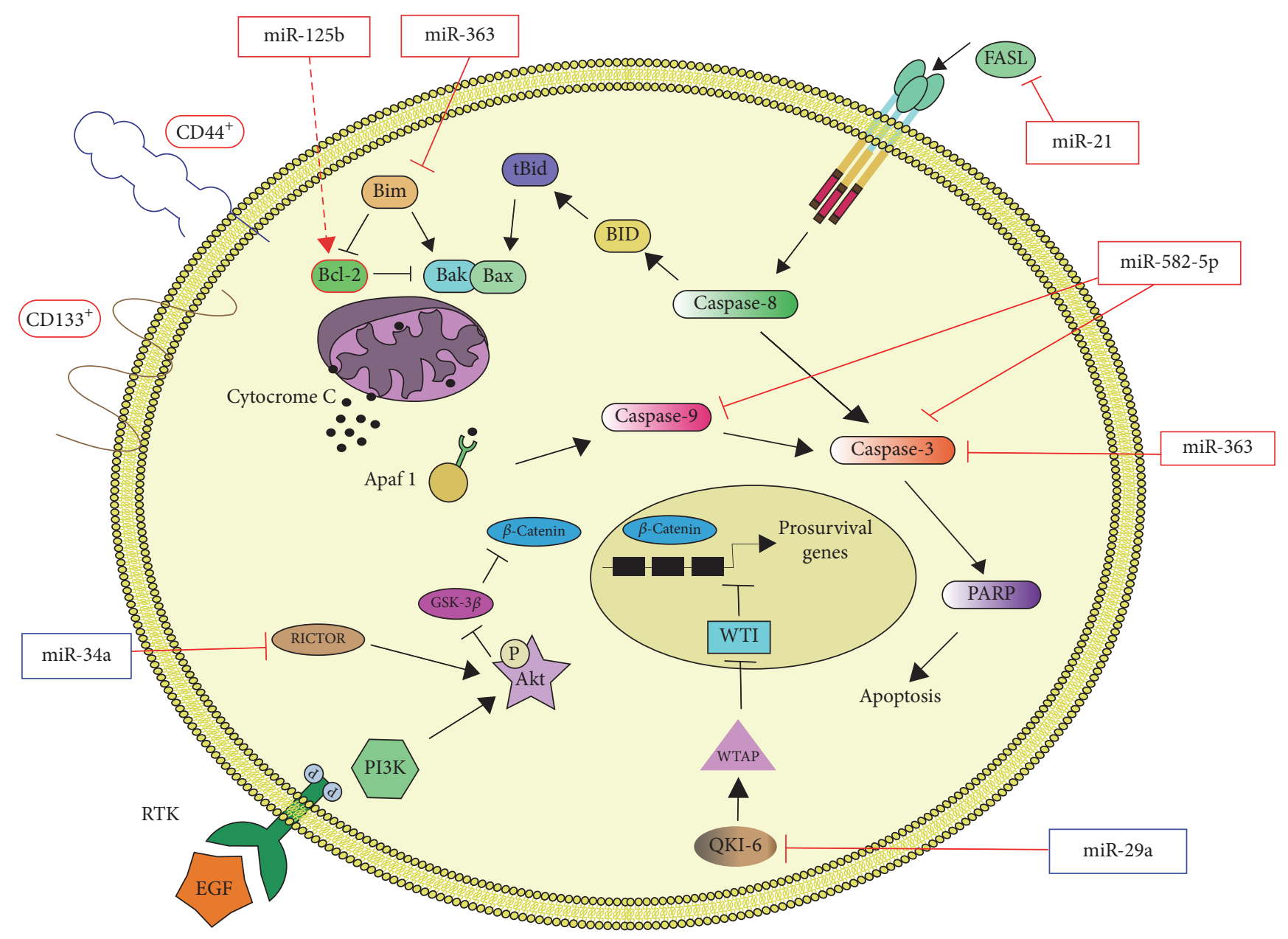

FIGURE 2: miRNAs in GSC Apoptosis. Schematic representation of the interactions between miRNAs and apoptosis signals in GSCs. Red lines represent the findings discussed in text (solid lines for direct and dashed lines for indirect regulation) while black lines represent established apoptotic pathways. Framed miRNAs or proteins indicate whether they are overexpressed (red frame) or underexpressed (blue frame) in GSCs.

treatment of glioblastoma neurosphere cells with AT induces apoptosis by increasing caspase-3 cleavage. AT reduces the expression of Hedgehog pathway target genes, such as PTCH1, N-Myc, and GLI2, but also the expression of the Notch pathway target genes HES1, HES5, and HEY1 and that of the pluripotency factor SOX2 [103]. These data suggest that apoptosis-induction by AT may be caused by impairment in multiple pathways controlling stemness.

4.3. Role of microRNAs (miRNAs) in GSC Apoptosis. At present, studies analyzing the cellular processes regulated by miRNAs in GSCs are scarce. However, as for other CSC, miRNAs seem to play key roles in apoptosis, differentiation, proliferation, migration, and invasion, as well as resistance of GSCs. In this section, we present the linkage of miRNAs to the signaling controlling apoptosis in GSCs (summarized in Figure 2). This information supports the idea that miRNAs can be potential therapeutic targets for the eradication of GSCs, as previously proposed $[76,77]$.
MiR-125b is overexpressed in CD133 ${ }^{+}$GSCs and its expression correlates with increased resistance to Temozolomide $[104,105]$. A reduction in the expression of miR-125b2 in combination with Temozolomide leads to apoptosis in GSCs by decreasing BCL-2 expression and increasing Bax, cytochrome c, Apaf-1, casapase-3, and poly-ADP-rybose polymerase (PARP) proteins [104]. Furthermore, Bakl is a direct target of miR-125b in GSCs and its exogenous forced expression restores Temozolomide sensitivity [105]. Similarly, in breast cancer cells, miR-125b confers resistance to paclitaxel through suppression of Bak1 [106].

The expression of miR-21 is also increased in $\mathrm{CD}_{133^{+}}$enriched neurosphere cultures. In those cells, Fas ligand (FASL) is downregulated by miR-21; consequently, they have increased proliferation and reduced apoptosis. The inhibition of miR-21 increases FASL expression and induces apoptosis [107], probably due to the FAS-mediated activation of the caspase cascade. Similarly, miR-582-5p and miR-363 are overexpressed in $\mathrm{CD}_{133^{+}}$human GSCs in comparison to 
$\mathrm{CD} 33^{+}$normal neural stem cells. In GSCs, miR-582-5p and miR-363 target caspase-3, caspase-9, and Bim. Accordingly, the inhibition of the microRNAs restores the expression of targets and leads to decreased cell growth and increased apoptosis [108].

On the other hand, the expression of miR-34a is lower in glioma compared to normal brain tissue and in $\mathrm{CD} 44^{+}$enriched glioma cell lines compared with nontumorigenic neural stem cells. MiR-34a targets Rictor, a component of the mTORC2 complex. Thus, ectopic overexpression of miR34a in GSCs downregulates Rictor, impairing AKT phosphorylation. Reduced activation of AKT, in turn, increases the levels of glycogen synthase kinase-3 $\beta$ (GSK-3 $\beta$ ) and the degradation of $\beta$-catenin. Consequently $\beta$-catenin target genes, such as c-Myc and Cyclin D1, are downregulated causing cell cycle arrest and apoptosis [109].

Recently, it has been reported that miR-29a expression is reduced in $\mathrm{CD}_{133^{+}}$GSCs in comparison with that of $\mathrm{CD}_{133^{-}}$nonstem cells. MiR-29a negatively regulates the expression of Quaking gene isoform 6 (QKI-6) by binding to its $3^{\prime}$-UTR. QKI-6 promotes the expression of WTAP [110], which in turn interacts with and inhibits the activity of the transcriptional repressor Wilms Tumor protein 1 (WT1) [111]. Thus, a lower level of miR-29a in GSCs releases the WT1mediated repression of key prosurvival target genes, such as EGFR [112], and promotes the activation of the PI3K pathway [110]. Consequently, miR29a is a tumor suppressor in GMB and its loss allows GSCs to have continuous activation of pathways controlling both invasion and survival.

\section{Conclusions}

Induction of apoptosis in GBM has showed limited benefits to date. However, clarification of the precise apoptotic mechanism altered in each GBM molecular subtype can develop subtype-specific therapies in the future. Moreover, the development of new therapeutic strategies should consider the presence of GSCs within GBM tumors. GSCs and nonstem GBM cells show common characteristics but also substantial differences. For example, PI3K/AKT/mTOR pathway is deregulated in both subpopulations but the impact of stemness-related pathways or miRNAs in GSCs apoptosis is quite unique.

Thus, in order to increase overall survival of GMB patients, we still require basic and clinical research that focuses on the apoptosis signaling pathways. We foresee that such investigations will uncover new targets for therapeutic intervention.

\section{Conflicts of Interest}

The authors declare that they have no conflicts of interest.

\section{Authors' Contributions}

All authors participated in the writing of the manuscript and read and approved its final version.

\section{Acknowledgments}

This work was supported by UNAM-PAPIIT IN228616 and CONACYT 221103 (Marco A. Velasco-Velázquez). Diana Casique-Aguirre is recipient of a Scholarship from the DGAPA-UNAM Postdoctoral Program. The authors thank Dr. Susana Castro-Obregon for the review and suggestions to this work and Mrs. Josefina Bolado, Head of the Scientific Paper Translation Department, from División de Investigación at Facultad de Medicina UNAM, for editing the English-language version of this manuscript.

\section{References}

[1] D. N. Louis, H. Ohgaki, and O. D. Wiestler, "The 2007 WHO classification of tumours of the central nervous system," Acta Neuropathologica, vol. 114, no. 2, pp. 97-109, 2007.

[2] I. A. Ho and W. S. Shim, "Contribution of the microenvironmental niche to glioblastoma heterogeneity," BioMed Research International, vol. 2017, pp. 1-13, 2017.

[3] R. Stupp, M. E. Hegi, W. P. Mason et al., "Effects of radiotherapy with concomitant and adjuvant temozolomide versus radiotherapy alone on survival in glioblastoma in a randomised phase III study: 5-year analysis of the EORTC-NCIC trial," The Lancet Oncology, vol. 10, no. 5, pp. 459-466, 2009.

[4] A. Sottoriva, I. Spiteri, S. G. M. Piccirillo et al., "Intratumor heterogeneity in human glioblastoma reflects cancer evolutionary dynamics," Proceedings of the National Acadamy of Sciences of the United States of America, vol. 110, no. 10, pp. 4009-4014, 2013.

[5] H. S. Friedman, T. Kerby, and H. Calvert, "Temozolomide and treatment of malignant glioma," Clinical Cancer Research, vol. 6, no. 7, pp. 2585-2597, 2000.

[6] C. R. Miller and A. Perry, "Glioblastoma: morphologic and molecular genetic diversity," Archives of Pathology \& Laboratory Medicine. College of American Pathologists, vol. 131, pp. 397-406, 2007.

[7] H. Ohgaki, P. Dessen, B. Jourde et al., "Genetic pathways to glioblastoma: a population-based study," Cancer Research, vol. 64, no. 19, pp. 6892-6899, 2004.

[8] J. L. Izquierdo-Garcia, P. Viswanath, P. Eriksson et al., "Metabolic reprogramming in mutant IDH1 glioma cells," PLoS ONE, vol. 10, no. 2, Article ID e0118781, 2015.

[9] "Comprehensive genomic characterization defines human glioblastoma genes and core pathways. Nature. Macmillan Publishers Limited. 2008; 455: 1061-8".

[10] R. G. W. Verhaak, K. A. Hoadley, E. Purdom et al., "Integrated genomic analysis identifies clinically relevant subtypes of glioblastoma characterized by abnormalities in PDGFRA, IDH1, EGFR, and NF1," Cancer Cell, vol. 17, pp. 98-110, 2010.

[11] Q.-W. Fan and W. A. Weiss, "Inhibition of PI3K-Akt-mTOR signaling in glioblastoma by mTORC1/2 inhibitors," Methods in Molecular Biology, vol. 821, pp. 349-359, 2012.

[12] "Phase II Study of BKM120 for subjects with recurrent glioblastoma," https://clinicaltrials.gov/ct2/show/NCT01339052.

[13] W. J. Wang, L. M. Long, N. Yang et al., "NVP-BEZ235, a novel dual PI3K/mTOR inhibitor, enhances the radiosensitivity of human glioma stem cells in vitro," Acta Pharmacologica Sinica, vol. 34, no. 5, pp. 681-690, 2013.

[14] E. Galanis, J. C. Buckner, M. J. Maurer et al., "Phase II trial of temsirolimus (CCI-779) in recurrent glioblastoma multiforme: 
a north central cancer treatment group study," Journal of Clinical Oncology, vol. 23, no. 23, pp. 5294-5304, 2005.

[15] G. J. Kubicek, M. Werner-Wasik, M. Machtay et al., "Phase I trial using proteasome inhibitor bortezomib and concurrent temozolomide and radiotherapy for central nervous system malignancies," International Journal of Radiation Oncology, Biology, Physics, vol. 74, no. 2, pp. 433-439, 2009.

[16] I. Coupienne, S. Bontems, M. Dewaele et al., "NF-kappaB inhibition improves the sensitivity of human glioblastoma cells to 5-aminolevulinic acid-based photodynamic therapy," Biochemical Pharmacology, vol. 81, no. 5, pp. 606-616, 2011.

[17] T. Fukushima, M. Kawaguchi, K. Yorita et al., "Antitumor effect of dehydroxymethylepoxyquinomicin, a small molecule inhibitor of nuclear factor-kB, on glioblastoma," Neuro-Oncology, vol. 14, no. 1, pp. 19-28, 2012.

[18] K. E. Tagscherer, A. Fassl, B. Campos et al., "Apoptosisbased treatment of glioblastomas with ABT-737, a novel small molecule inhibitor of Bcl-2 family proteins," Oncogene, vol. 27, no. 52, pp. 6646-6656, 2008.

[19] J. B. Fiveash, S. A. Chowdhary, D. Peereboom et al., "NABTT0702: A phase II study of R-(-)-gossypol (AT-101) in recurrent glioblastoma multiforme (GBM)," Journal of Clinical Oncology American Society of Clinical Oncology, vol. 27, 2009.

[20] G. Karpel-Massler, C. Shu, L. Chau et al., "Combined inhibition of Bcl-2/Bcl-xL and Usp9X/Bag3 overcomes apoptotic resistance in glioblastoma in vitro and in vivo," Oncotarget , vol. 6, pp. 14507-14521, 2015.

[21] D. S. Ziegler, R. D. Wright, S. Kesari et al., "Resistance of human glioblastoma multiforme cells to growth factor inhibitors is overcome by blockade of inhibitor of apoptosis proteins," The Journal of Clinical Investigation, vol. 118, no. 9, pp. 3109-3122, 2008.

[22] L. Wagner, V. Marschall, S. Karl et al., "Smac mimetic sensitizes glioblastoma cells to Temozolomide-induced apoptosis in a RIP1- and NF- $\kappa$ B-dependent manner," Oncogene, vol. 32, no. 8, pp. 988-997, 2013.

[23] S. Fulda, W. Wick, M. Weller, and K.-M. Debatin, "Smac agonists sensitize for Apo2L/TRAIL-or anticancer drug-induced apoptosis and induce regression of malignant glioma in vivo," Nature Medicine, vol. 8, no. 8, pp. 808-815, 2002.

[24] M. A. García, A. Ramírez, E. López-Ruiz et al., "Apoptosis as a therapeutic target in cancer and cancer stem cells: novel strategies and futures perspectives. Citeseer; 2012".

[25] I. M. Ghobrial, T. E. Witzig, and A. A. Adjei, "Targeting apoptosis pathways in cancer therapy," CA: A Cancer Journal for Clinicians, vol. 55, no. 3, pp. 178-194, 2005.

[26] L. C. Cantley, "The phosphoinositide 3-kinase pathway," Science, vol. 296, no. 5573, pp. 1655-1657, 2002.

[27] T. F. Franke, C. P. Hornik, L. Segev, G. A. Shostak, and C. Sugimoto, "PI3K/Akt and apoptosis: size matters," Oncogene, vol. 22, no. 56, pp. 8983-8998, 2003.

[28] S. R. Datta, A. Brunet, and M. E. Greenberg, "Cellular survival: a play in three akts," Genes \& Development, vol. 13, no. 22, pp. 2905-2927, 1999.

[29] H. Mao, D. G. Lebrun, J. Yang, V. F. Zhu, and M. Li, "Deregulated signaling pathways in glioblastoma multiforme: molecular mechanisms and therapeutic targets," Cancer Investigation, vol. 30, no. 1, pp. 48-56, 2012.

[30] H. Wang, H. Wang, W. Zhang, H. J. Huang, W. S. L. Liao, and G. N. Fuller, "Analysis of the activation status of Akt, NF $\kappa$ B, and
Stat3 in human diffuse gliomas," Laboratory Investigation, vol. 84, no. 8, pp. 941-951, 2004.

[31] M.-E. Halatsch, U. Schmidt, A. Unterberg, and V. I. Vougioukas, "Uniform MDM2 overexpression in a panel of glioblastoma multiforme cell lines with divergent EGFR and p53 expression status," Anticancer Reseach, vol. 26, pp. 4191-4194, 2006.

[32] B. Costa, S. Bendinelli, P. Gabelloni et al., "Human glioblastoma multiforme: 53 reactivation by a novel MDM2 inhibitor," PLoS ONE, vol. 8, no. 8, Article ID e72281, 2013.

[33] S. Daniele, B. Costa, E. Zappelli et al., "Combined inhibition of AKT/mTOR and MDM2 enhances Glioblastoma Multiforme cell apoptosis and differentiation of cancer stem cells," Scientific Reports, vol. 5, article 9956, 2015.

[34] S. R. Datta, H. Dudek, T. Xu et al., "Akt phosphorylation of BAD couples survival signals to the cell- intrinsic death machinery," Cell, vol. 91, no. 2, pp. 231-241, 1997.

[35] Z. Duzgun, Z. Eroglu, and C. Biray Avci, "Role of mTOR in glioblastoma," Gene, vol. 575, no. 2, pp. 187-190, 2016.

[36] L. Lisi, E. Laudati, P. Navarra, and C. Dello Russo, “The mTOR kinase inhibitors polarize glioma-activated microglia to express a M1 phenotype," Journal of Neuroinflammation, vol. 11, no. 1, article no. 125, 2014.

[37] R. Endersby and S. J. Baker, "PTEN signaling in brain: Neuropathology and tumorigenesis," Oncogene, vol. 27, no. 41, pp. 5416-5430, 2008.

[38] Y. Yang, N. Shao, G. Luo et al., "Mutations of PTEN gene in gliomas correlate to tumor differentiation and short-term survival rate," Anticancer Reseach, vol. 30, no. 3, pp. 981-985, 2010.

[39] B. K. A. Rasheed, T. T. Stenzel, R. E. McLendon et al., "PTEN gene mutations are seen in high-grade but not in low-grade gliomas," Cancer Research, vol. 57, no. 19, pp. 4187-4190, 1997.

[40] Y. Yang, N. Shao, G. Luo, L. Li, P. Nilsson-Ehle, and N. Xu, "Relationship between PTEN gene expression and differentiation of human glioma," Scandinavian Journal of Clinical \& Laboratory Investigation, vol. 66, no. 6, pp. 469-475, 2006.

[41] D. Koul, "PTEN Signaling pathways in glioblastoma," Cancer Biology \& Therapy, vol. 7, no. 9, pp. 1321-1325, 2008.

[42] J.-J. Lee, B. C. Kim, M.-J. Park et al., "PTEN status switches cell fate between premature senescence and apoptosis in glioma exposed to ionizing radiation," Cell Death \& Differentiation, vol. 18, no. 4, pp. 666-677, 2011.

[43] V. K. Hill, J. Kim, C. D. James, T. Waldman, and S. Deb, "Correction of PTEN mutations in glioblastoma cell lines via AAV-mediated gene editing," PLoS ONE, vol. 12, no. 5, Article ID e0176683, 2017.

[44] D. B. T. Cox, R. J. Platt, and F. Zhang, "Therapeutic genome editing: prospects and challenges," Nature Medicine, vol. 21, no. 2, pp. 121-131, 2015.

[45] S. Chen, H. Sun, K. Miao, and C.-X. Deng, "CRISPR-Cas9: from genome editing to cancer research," International Journal of Biological Sciences, vol. 12, no. 12, pp. 1427-1436, 2016.

[46] N. D. Perkins, "Integrating cell-signalling pathways with NFkappaB and IKK function," Nature Reviews Molecular Cell Biology, vol. 8, pp. 49-62, 2007.

[47] M. Hinz and C. Scheidereit, "The $\mathrm{I} \kappa \mathrm{B}$ kinase complex in NF- $\kappa \mathrm{B}$ regulation and beyond," EMBO Reports, vol. 15, no. 1, pp. 46-61, 2014.

[48] M. Chaves, T. Eissing, and F. Allgöwer, "Regulation of apoptosis via the NF $\kappa$ B pathway: modeling and analysis," in Dynamics on 
complex networks, N. Ganguly, A. Deuchst, and A. Mukherjee, Eds., Modeling and Simulation in Science, Engineering and Technology, pp. 19-33, Boston, Mass, USA, 2009.

[49] P. Korkolopoulou, G. Levidou, A. A. Saetta et al., "Expression of nuclear factor- $\kappa \mathrm{B}$ in human astrocytomas: relation to $\mathrm{pI} \kappa \mathrm{Ba}$, vascular endothelial growth factor, Cox-2, microvascular characteristics, and survival," Human Pathology, vol. 39, no. 8, pp. 1143-1152, 2008.

[50] G. P. Atkinson, S. E. Nozell, and E. N. Benveniste, "NF- $\kappa$ B and STAT3 signaling in glioma: Targets for future therapies," Expert Review of Neurotherapeutics, vol. 10, no. 4, pp. 575-586, 2010.

[51] D. Bai, L. Ueno, and P. K. Vogt, "Akt-mediated regulation of $\mathrm{NF} \kappa \mathrm{B}$ and the essentialness of $\mathrm{NF} \kappa \mathrm{B}$ for the oncogenicity of PI3K and Akt," International Journal of Cancer, vol. 125, no. 12, pp. 2863-2870, 2009.

[52] B. Kaltschmidt, C. Kaltschmidt, T. G. Hofmann, S. P. Hehner, W. Dröge, and M. L. Schmitz, "The pro- or anti-apoptotic function of NF- $\kappa$ B is determined by the nature of the apoptotic stimulus," European Journal of Biochemistry, vol. 267, no. 12, pp. 3828-3835, 2000.

[53] C.-Y. Wang, M. W. Mayo, R. G. Korneluk, D. V. Goeddel, and A. S. Baldwin Jr., "NF-kappaB antiapoptosis: induction of TRAF1 and TRAF2 and c-IAP1 and c-IAP2 to suppress caspase8 activation," Science, vol. 281, no. 5383, pp. 1680-1683, 1998.

[54] S. Hayashi, M. Yamamoto, Y. Ueno et al., "Expression of nuclear factor- $\kappa \mathrm{B}$, tumor necrosis factor receptor type 1, and c-Myc in human astrocytomas," Neurologia Medico-Chirurgica, vol. 41, no. 4, pp. 187-195, 2001.

[55] "Bortezomib, temozolomide, and regional radiation therapy in treating patients with newly diagnosed glioblastoma multiforme or gliosarcoma," https://www.clinicaltrials.gov/ct2/ show/NCT00998010?term=NCT00998010\&amp;rank=1.

[56] L. G. Tone, "Inhibition of NF- $\kappa \mathrm{B}$ by dehydroxymethylepoxyquinomicin suppresses invasion and synergistically potentiates temozolomide and $\gamma$-radiation cytotoxicity in glioblastoma cells," Chemotherapy Research and Practice, vol. 2013, Article ID 593020, 16 pages, 2013.

[57] J. Marie Hardwick and L. Soane, "Multiple functions of BCL-2 family proteins," Cold Spring Harbor Perspectives in Biology, vol. 5, no. 2, 2013.

[58] D. de Jong, F. A. Prins, D. Y. Mason, J. C. Reed, G. B. van Ommen, and P. M. Kluin, "Subcellular localization of the bcl2 protein in malignant and normal lymphoid cells," Cancer Research, vol. 54, no. 1, pp. 256-260, 1994.

[59] S. Cory, D. C. S. Huang, and J. M. Adams, "The Bcl-2 family: roles in cell survival and oncogenesis," Oncogene, vol. 22, no. 53, pp. 8590-8607, 2003.

[60] S. Shimizu, M. Narita, and Y. Tsujimoto, "Bcl-2 family proteins regulate the release of apoptogenic cytochrome $\mathrm{c}$ by the mitochondrial channel VDAC," Nature, vol. 399, no. 6735, pp. 483487, 1999.

[61] B. Qiu, Y. Wang, J. Tao, and Y. Wang, "Expression and correlation of Bcl-2 with pathological grades in human glioma stem cells," Oncology Reports, vol. 28, no. 1, pp. 155-160, 2012.

[62] H. Strik, M. Deininger, J. Streffer et al., "BCL-2 family protein expression in initial and recurrent glioblastomas: modulation by radiochemotherapy," Journal of Neurology, Neurosurgery \& Psychiatry, vol. 67, no. 6, pp. 763-768, 1999.

[63] Z. Jiang, X. Zheng, and K. M. Rich, "Down-regulation of Bcl2 and $\mathrm{Bcl}-\mathrm{xL}$ expression with bispecific antisense treatment in glioblastoma cell lines induce cell death," Journal of Neurochemistry, vol. 84, no. 2, pp. 273-281, 2003.

[64] V. Voss, C. Senft, V. Lang et al., "The pan-Bcl-2 inhibitor (-)gossypol triggers autophagic cell death in malignant glioma," Molecular Cancer Research, vol. 8, no. 7, pp. 1002-1016, 2010.

[65] T. Tencho, A. Zachariou, R. Wilson, M. Ditzel, and P. Meier, "IAPs are functionally non-equivalent and regulate effector caspases through distinct mechanisms," Nature Cell Biology, vol. 7, no. 1, pp. 70-77, 2005.

[66] K. H. Khan, M. Blanco-Codesido, and L. R. Molife, "Cancer therapeutics: targeting the apoptotic pathway," Critical Review in Oncology/Hematology, vol. 90, no. 3, pp. 200-219, 2014.

[67] R. G. Weber, C. Sommer, F. K. Albert, M. Kiessling, and T. Cremer, "Clinically distinct subgroups of glioblastoma multiforme studied by comparative genomic hybridization," Laboratory Investigation, vol. 74, no. 1, pp. 108-119, 1996.

[68] W. Yang, M. Cooke, C. S. Duckett, X. Yang, and J. F. Dorsey, "Distinctive effects of the cellular inhibitor of apoptosis protein c-IAP2 through stabilization by XIAP in glioblastoma multiforme cells," Cell Cycle, vol. 13, no. 6, pp. 992-1005, 2014.

[69] B. Wagenknecht, T. Glaser, U. Naumann et al., "Expression and biological activity of X-linked inhibitor of apoptosis (XIAP) in human malignant glioma," Cell Death \& Differentiation, vol. 6, no. 4, pp. 370-376, 1999.

[70] P. L. C. Lopez, E. C. Filippi-Chiela, A. O. Silva et al., "Sensitization of glioma cells by X-linked inhibitor of apoptosis protein knockdown," Oncology, vol. 83, no. 2, pp. 75-82, 2012.

[71] H-N. Zhen, L-W. Li, W. Zhang et al., "Short hairpin RNA targeting survivin inhibits growth and angiogenesis of glioma U251 cells," International Journal of Oncology, vol. 31, pp. 11111118, 1992.

[72] T. Sun, N. M. Warrington, J. Luo et al., "Sexually dimorphic RB inactivation underlies mesenchymal glioblastoma prevalence in males," The Journal of Clinical Investigation, vol. 124, no. 9, pp. 4123-4133, 2014.

[73] A. P. Patel, I. Tirosh, J. J. Trombetta et al., "Single-cell RNA-seq highlights intratumoral heterogeneity in primary glioblastoma," Science, vol. 344, no. 6190, pp. 1396-1401, 2014.

[74] M. Greaves and C. C. Maley, "Clonal evolution in cancer," Nature, vol. 481, no. 7381, pp. 306-313, 2012.

[75] J. N. Rich, "Cancer stem cells: understanding tumor hierarchy and heterogeneity," Medicine, vol. 95, no. 1, pp. S2-S7, 2016.

[76] A. R. Safa, M. R. Saadatzadeh, A. A. Cohen-Gadol, K. E. Pollok, and K. Bijangi-Vishehsaraei, "Glioblastoma stem cells (GSCs) epigenetic plasticity and interconversion between differentiated non-GSCs and GSCs," Genes \& Diseases, vol. 2, no. 2, pp. 152163, 2015.

[77] A. U. Ahmed, B. Auffinger, and M. S. Lesniak, "Understanding glioma stem cells: rationale, clinical relevance and therapeutic strategies," Expert Review of Neurotherapeutics, vol. 13, no. 5, pp. 545-555, 2013.

[78] D. V. Brown, G. Filiz, P. M. Daniel et al., "Expression of CD133 and CD44 in glioblastoma stem cells correlates with cell proliferation, phenotype stability and intratumor heterogeneity," PLoS ONE, vol. 12, no. 2, Article ID e0172791, 2017.

[79] B. D. Liebelt, T. Shingu, X. Zhou, J. Ren, S. A. Shin, and J. Hu, "Glioma stem cells: signaling, microenvironment, and therapy," Stem Cells International, vol. 2016, Article ID 7849890, 10 pages, 2016. 
[80] P. Brescia, B. Ortensi, L. Fornasari, D. Levi, G. Broggi, and G. Pelicci, "CD133 is essential for glioblastoma stem cell maintenance," Stem Cells, vol. 31, no. 5, pp. 857-869, 2013.

[81] M. Jhanwar-Uniyal, M. Labagnara, M. Friedman, A. Kwasnicki, and R. Murali, "Glioblastoma: molecular pathways, stem cells and therapeutic targets," Cancers, vol. 7, no. 2, pp. 538-555, 2015.

[82] A. Toren, B. Bielorai, J. Jacob-Hirsch et al., "CD133-positive hematopoietic stem cell "sternness" genes contain many genes mutated or abnormally expressed in leukemia," Stem Cells, vol. 23, no. 8, pp. 1142-1153, 2005.

[83] W. Hilbe, S. Dirnhofer, F. Oberwasserlechner et al., "CD133 positive endothelial progenitor cells contribute to the tumour vasculature in non-small cell lung cancer," Journal of Clinical Pathology, vol. 57, no. 9, pp. 965-969, 2004.

[84] I. Shibahara, Y. Sonoda, R. Saito et al., "The expression status of CD133 is associated with the pattern and timing of primary glioblastoma recurrence," Neuro-Oncology, vol. 15, no. 9, pp. 1151-1159, 2013.

[85] H. Ponta, L. Sherman, and P. A. Herrlich, "CD44: from adhesion molecules to signalling regulators," Nature Reviews Molecular Cell Biology, vol. 4, no. 1, pp. 33-45, 2003.

[86] E. Olsson, G. Honeth, P.-O. Bendahl et al., "CD44 isoforms are heterogeneously expressed in breast cancer and correlate with tumor subtypes and cancer stem cell markers," BMC Cancer, vol. 11, article 418, 2011.

[87] L. Du, H. Wang, L. He et al., "CD44 is of functional importance for colorectal cancer stem cells," Clinical Cancer Research, vol. 14, no. 21, pp. 6751-6760, 2008.

[88] Z. Gadhoum, M.-P. Leibovitch, J. Oi et al., "CD44: a new means to inhibit acute myeloid leukemia cell proliferation via p27Kip1," Blood, vol. 103, no. 3, pp. 1059-1068, 2004.

[89] A. Pietras, A. M. Katz, E. J. Ekström et al., “Osteopontin-CD44 signaling in the glioma perivascular niche enhances cancer stem cell phenotypes and promotes aggressive tumor growth," Cell Stem Cell, vol. 14, no. 3, pp. 357-369, 2014.

[90] K. C. Wei, C. Y. Huang, P. Y. Chen et al., "Evaluation of the prognostic value of CD44 in glioblastoma multiforme," Anticancer Research, vol. 30, pp. 253-259, 2010.

[91] P. Mao, K. Joshi, J. Li et al., "Mesenchymal glioma stem cells are maintained by activated glycolytic metabolism involving aldehyde dehydrogenase 1A3," Proceedings of the National Acadamy of Sciences of the United States of America, vol. 110, no. 21, pp. 8644-8649, 2013.

[92] D. V. Brown, P. M. Daniel, G. M. D’Abaco et al., "Coexpression analysis of CD133 and CD44 identifies Proneural and Mesenchymal subtypes of glioblastoma multiforme," Oncotarget , vol. 6, no. 8, pp. 6267-6280, 2015.

[93] A. Dubrovska, J. Elliott, R. J. Salamone et al., "Combination therapy targeting both tumor-initiating and differentiated cell populations in prostate carcinoma," Clinical Cancer Research, vol. 16, no. 23, pp. 5692-5702, 2010.

[94] Y. Hu, R. Guo, J. Wei et al., "Effects of PI3K inhibitor NVPBKM120 on overcoming drug resistance and eliminating cancer stem cells in human breast cancer cells," Cell Death \& Disease, vol. 6, no. 12, article no e2020, 2015.

[95] M. M. Sherry, A. Reeves, J. K. Wu, and B. H. Cochran, "STAT3 is required for proliferation and maintenance of multipotency in glioblastoma stem cells," Stem Cells, vol. 27, no. 10, pp. 23832392, 2009.

[96] L. G-H, H. Wei, L. S-Q, H. Ji, and D-L. Wang, "Knockdown of STAT3 expression by RNAi suppresses growth and induces apoptosis and differentiation in glioblastoma stem cells," International Journal of Oncology, vol. 37, pp. 103-110, 2010.

[97] T. Ashizawa, H. Miyata, A. Iizuka et al., "Effect of the STAT3 inhibitor STX-0119 on the proliferation of cancer stem-like cells derived from recurrent glioblastoma," International Journal of Oncology, vol. 43, no. 1, pp. 219-227, 2013.

[98] N. Wu, J. Liu, X. Zhao et al., "Cardamonin induces apoptosis by suppressing STAT3 signaling pathway in glioblastoma stem cells," Tumor Biology, vol. 36, no. 12, pp. 9667-9676, 2015.

[99] M. M. Lino, A. Merlo, and J.-L. Boulay, "Notch signaling in glioblastoma: a developmental drug target?" BMC Medicine, vol. 8, article no. 72, 2010.

[100] X. Fan, L. Khaki, T. S. Zhu et al., "NOTCH pathway blockade depletes CD133-positive glioblastoma cells and inhibits growth of tumor neurospheres and xenografts," Stem Cells, vol. 28, no. 1, pp. 5-16, 2010.

[101] J. Kim, J. J. Lee, J. Kim, D. Gardner, and P. A. Beachy, "Arsenic antagonizes the Hedgehog pathway by preventing ciliary accumulation and reducing stability of the Gli2 transcriptional effector," Proceedings of the National Acadamy of Sciences of the United States of America, vol. 107, no. 30, pp. 13432-13437, 2010.

[102] E. M. Beauchamp, L. Ringer, G. Bulut et al., "Arsenic trioxide inhibits human cancer cell growth and tumor development in mice by blocking Hedgehog/GLI pathway," The Journal of Clinical Investigation, vol. 121, no. 1, pp. 148-160, 2011.

[103] D. Ding, K. S. Lim, and C. G. Eberhart, "Arsenic trioxide inhibits Hedgehog, Notch and stem cell properties in glioblastoma neurospheres," Acta Neuropathologica Communications, vol. 2, no. 1, article no. 31, 2014.

[104] L. Shi, S. Zhang, K. Feng et al., "MicroRNA-125b-2 confers human glioblastoma stem cells resistance to temozolomide through the mitochondrial pathway of apoptosis," International Journal of Oncology, vol. 40, no. 1, pp. 119-129, 2012.

[105] J. Chen, X. Fu, Y. Wan, Z. Wang, D. Jiang, and L. Shi, “miR-125b inhibitor enhance the chemosensitivity of glioblastoma stem cells to temozolomide by targeting Bak1," Tumor Biology, vol. 35, no. 7, pp. 6293-6302, 2014.

[106] M. Zhou, Z. Liu, Y. Zhao et al., "MicroRNA-125b confers the resistance of breast cancer cells to paclitaxel through suppression of pro-apoptotic Bcl-2 antagonist killer 1 (Bak1) expression," The Journal of Biological Chemistry, vol. 285, no. 28, pp. 21496-21507, 2010.

[107] C. Shang, Y. Guo, Y. Hong, Y. Liu, and Y. Xue, "MiR-21 upregulation mediates glioblastoma cancer stem cells apoptosis and proliferation by targeting FASLG," Molecular Biology Reports, vol. 42, no. 3, pp. 721-727, 2015.

[108] D. H. Floyd, Y. Zhang, B. K. Dey et al., "Novel anti-apoptotic microRNAs 582-5p and 363 promote human glioblastoma stem cell survival via direct inhibition of caspase 3, caspase 9, and Bim," PLoS ONE, vol. 9, no. 5, Article ID e96239, 2014.

[109] S. S. Rathod, S. B. Rani, M. Khan, D. Muzumdar, and A. Shiras, "Tumor suppressive miRNA-34a suppresses cell proliferation and tumor growth of glioma stem cells by targeting Akt and Wnt signaling pathways," FEBS Open Bio, vol. 4, pp. 485-495, 2014.

[110] Z. Xi, P. Wang, Y. Xue et al., "Overexpression of miR-29a reduces the oncogenic properties of glioblastoma stem cells by downregulating Quaking gene isoform 6," Oncotarget, vol. 8, pp. 24949-24963, 2017. 
[111] N. A. Little, N. D. Hastie, and R. C. Davies, "Identification of WTAP, a novel Wilms' tumour 1-associating protein," Human Molecular Genetics, vol. 9, no. 15, pp. 2231-2239, 2000.

[112] C. Englert, X. Hou, S. Maheswaran et al., "WT1 suppresses synthesis of the epidermal growth factor receptor and induces apoptosis," EMBO Journal, vol. 14, no. 19, pp. 4662-4675, 1995. 


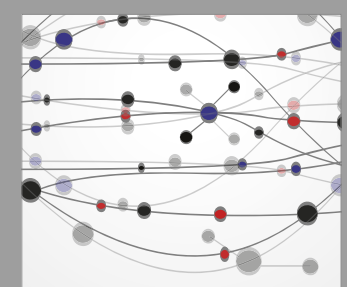

The Scientific World Journal
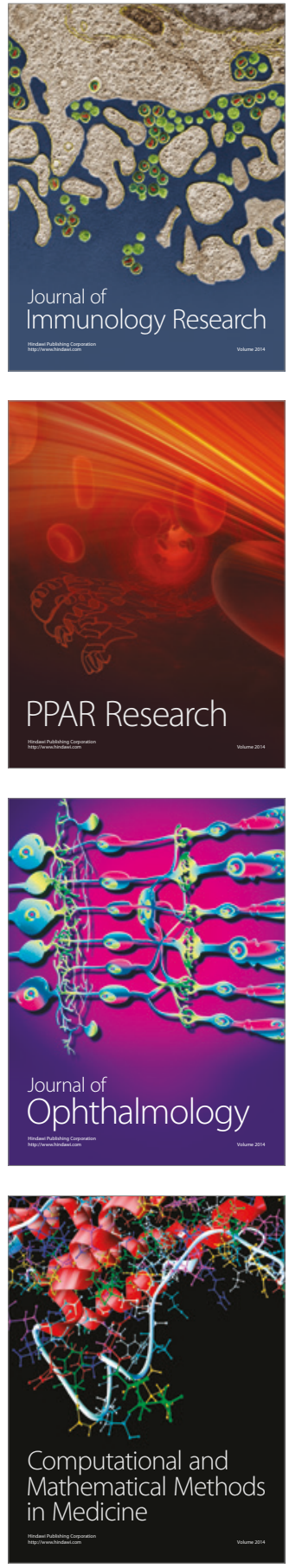

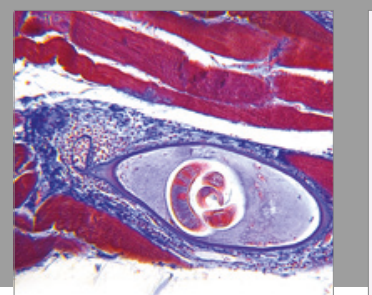

Gastroenterology Research and Practice
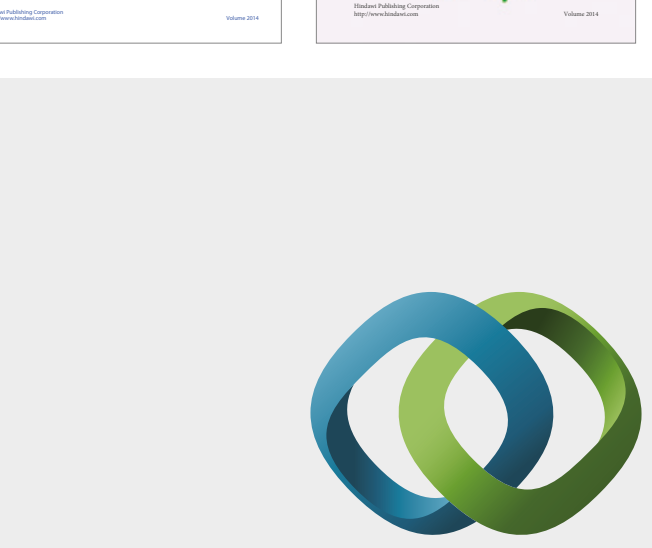

\section{Hindawi}

Submit your manuscripts at

https://www.hindawi.com
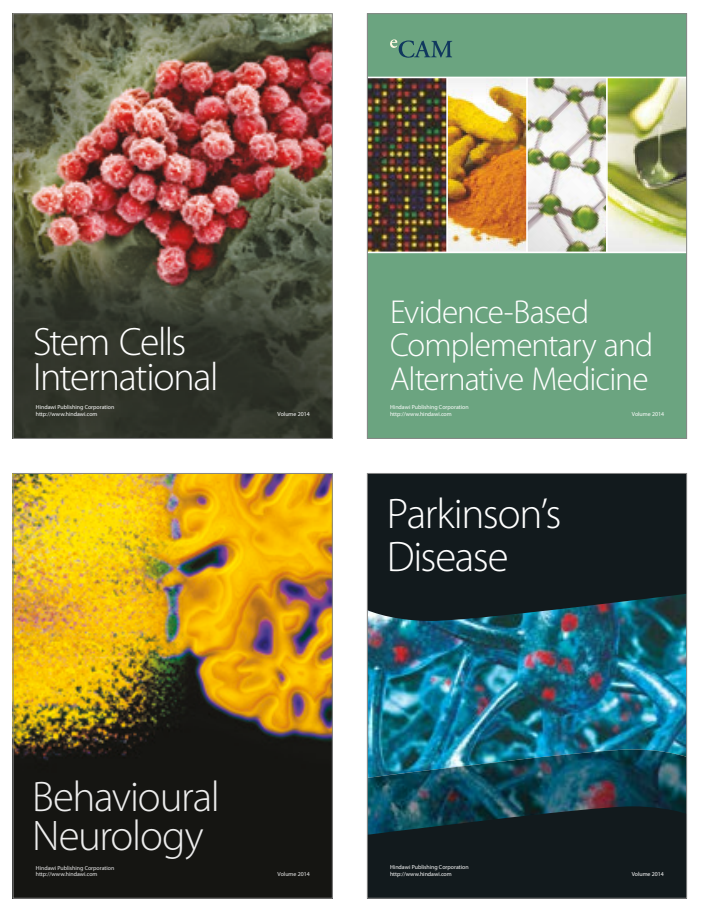
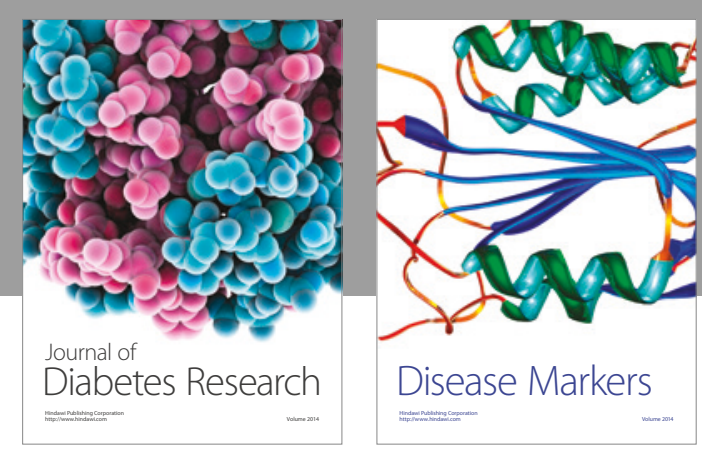

Disease Markers
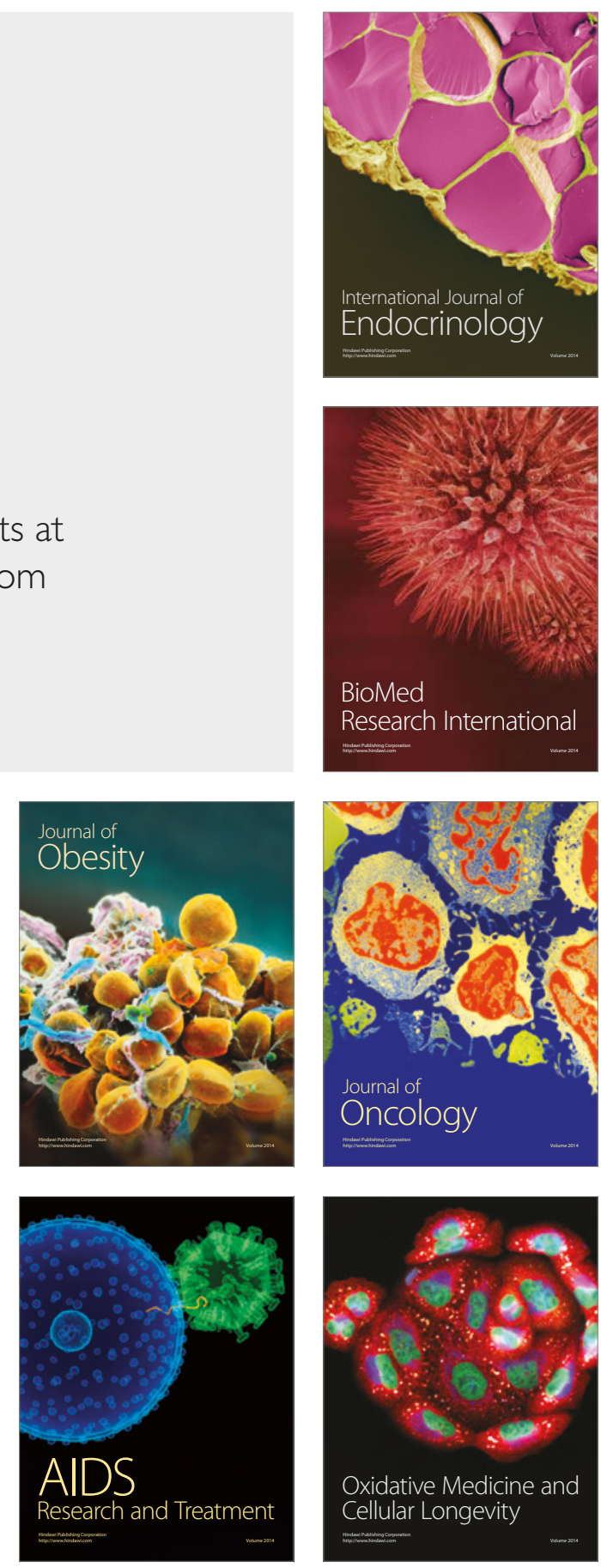